\title{
Establishing an Entertainment Engineering Curriculum
}

\author{
Robert F. Boehm \\ Mechanical Engineering Department \\ and \\ Joe Aldridge and Brackley Frayer \\ Theatre Department \\ University of Nevada Las Vegas \\ Las Vegas, NV 89154
}

\begin{abstract}
A new, multidisciplinary program in Entertainment Engineering and Design is being established at the University of Nevada Las Vegas. The name of the program could be defined in a number of ways because few programs of this type exist and the field is so broad. Our emphasis is on the application of technology to enhance the entertainment value of live shows and rides. Steps being taken to establish this program are outlined, starting with an undergraduate minor and moving to an undergraduate major. The role of entertainment-based businesses in the development of this new program is also described.
\end{abstract}

\section{Background}

Las Vegas has offered entertainment experiences to the world for many years. It started with the legalization of gambling (currently the somewhat more subtle name "gaming" is used) in the first third of the $20^{\text {th }}$ century. While the casino hotels still look to gaming to furnish a significant part of their income, their management has concluded that they can attract return customers more frequently and draw more new customers if they offer a broader range of entertainment experiences. Early approaches with the use of lounge acts still exist, but these have been supplemented with a variety of shows where technology is used to give additional dimensions to the entertainment experience.

It is hard to say when the trend started. Perhaps it was in 1973, when the Ziegfeld showroom opened at the MGM Grand (now Bally's). It was the precursor to most of the technology found in today's Las Vegas showrooms. Then came the design of the touring version of the Siegfried and Roy show in the late 1980s. Technological inventiveness was definitely a key ingredient of entertainment when the many new blockbuster hotels opened on the Las Vegas Strip in the early 1990s.

Most of the early technologically based shows were conceived, designed, and operated by people with a theatre background. Theatre has always had a technical side to it, but this has typically meant the ability to construct scenery, specify and set up lights, and a variety of other issues in traditional theatre. With the computer era came the ability to automate shows and to control

Proceedings of the 2005 American Society for Engineering Education Annual Conference \& Exposition Copyright (C) 2005, American Society for Engineering Education 
special effects that were not thought possible just a few years earlier. Although some theatre schools made their educational programs more technical to address this increase in complexity, some of the shows became much too technically based to be handled by the more traditionally trained theatre technicians.

The University of Nevada Las Vegas (UNLV) is a relatively young institution. While it has had some engineering courses offered since the 1960's, its College of Engineering was initiated in the late 1980's. With the exception of a limited number of technically based businesses as well as a US Department of Energy presence, very little industrial base exists in Las Vegas. In fact, the desire to diversify the economy was one of the motivations to set up the College of Engineering at UNLV.

In the early ' 90 s a series of discussions took place related to entertainment technology at UNLV between Departments in Engineering and the Theatre Department. It was clear that offering a program of this type which would bring engineering expertise to the live entertainment venues could serve a need in the industry. Without a clear precedent to learn from, little action besides discussions took place for several years.

In 2000, faculty from Engineering and Theatre decided to offer a trial course in the general area of entertainment engineering. Contact with local practitioners (theatrically trained people, engineers, designers and operators) found that the industry was extremely receptive to the concept of educating people in some combination of theatre and engineering.

A survey course was offered and has been repeated. New courses have been conceived and are being offered. Support of the industry continues to be manifest. This was particularly evident in a UNLV hosted "Conversation on Entertainment Engineering" (a meeting where roundtables were convened on this topic) between faculty and practitioners during the spring of 2003. People involved in the development of a possible program were encouraged to move forward.

The University has received much attention in the media for this program. See for example [1, 2, $3,4]$. This has ranged from articles in technical publications to a profile on National Public Radio.

Considerations in developing the program

The first problem faced in developing a new program of this type is to recognize that even when focusing on live entertainment venues, the range of possibilities is quite large. It can include heavy duty mechanical equipment, as is shown in Figure 1. Or it can incorporate some that use quite stylistic but involved concepts as demonstrated in many of the Cirque d Soliel shows (see an example in Figure 2). A totally different type of technology is found in the various types of road shows as is represented by a traveling ice show shown in Figure 3. 


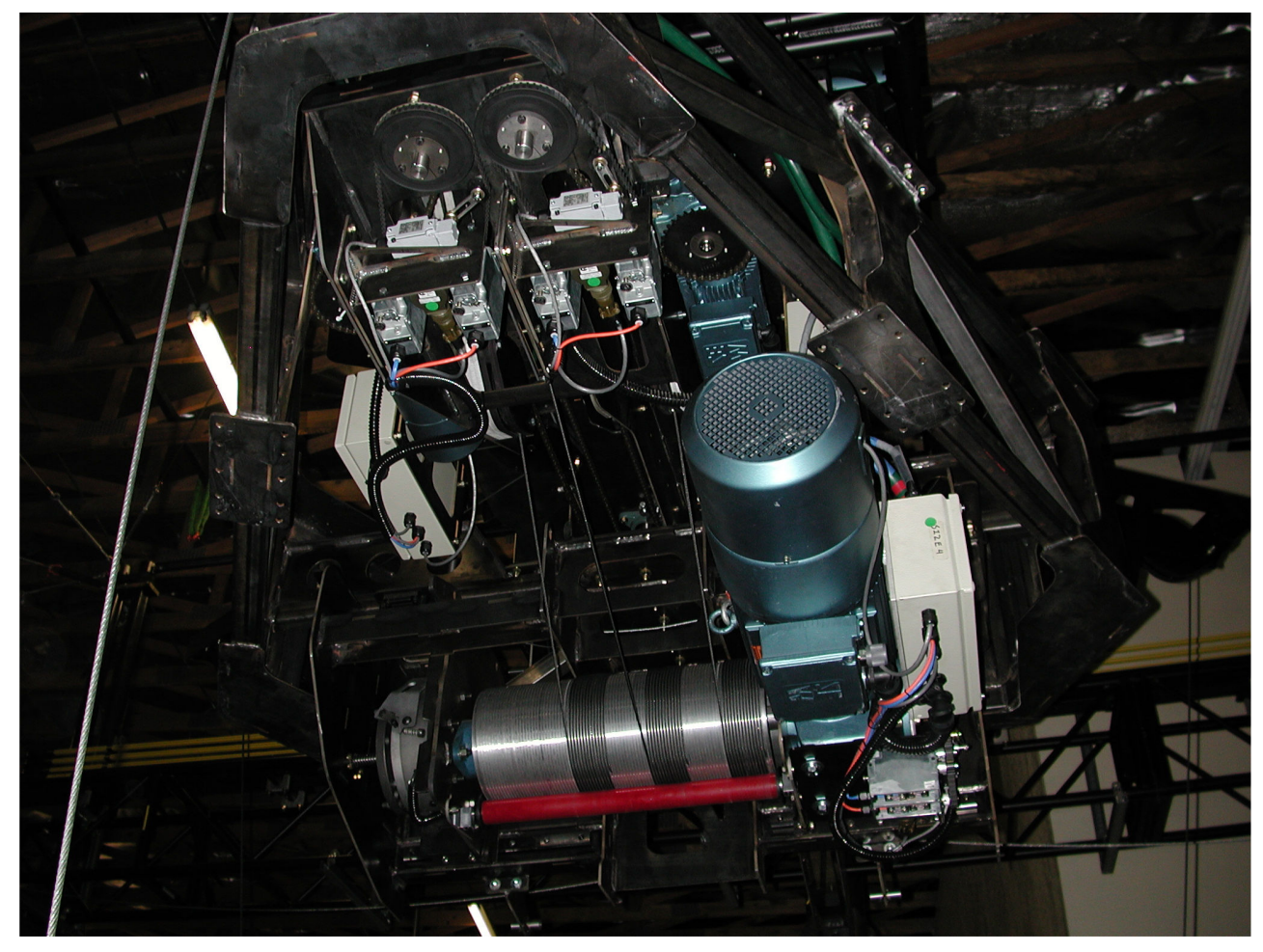

Figure 1. A modern lifting/traversing unit developed by Fisher Technical Services of Las Vegas for a live entertainment venue is shown.

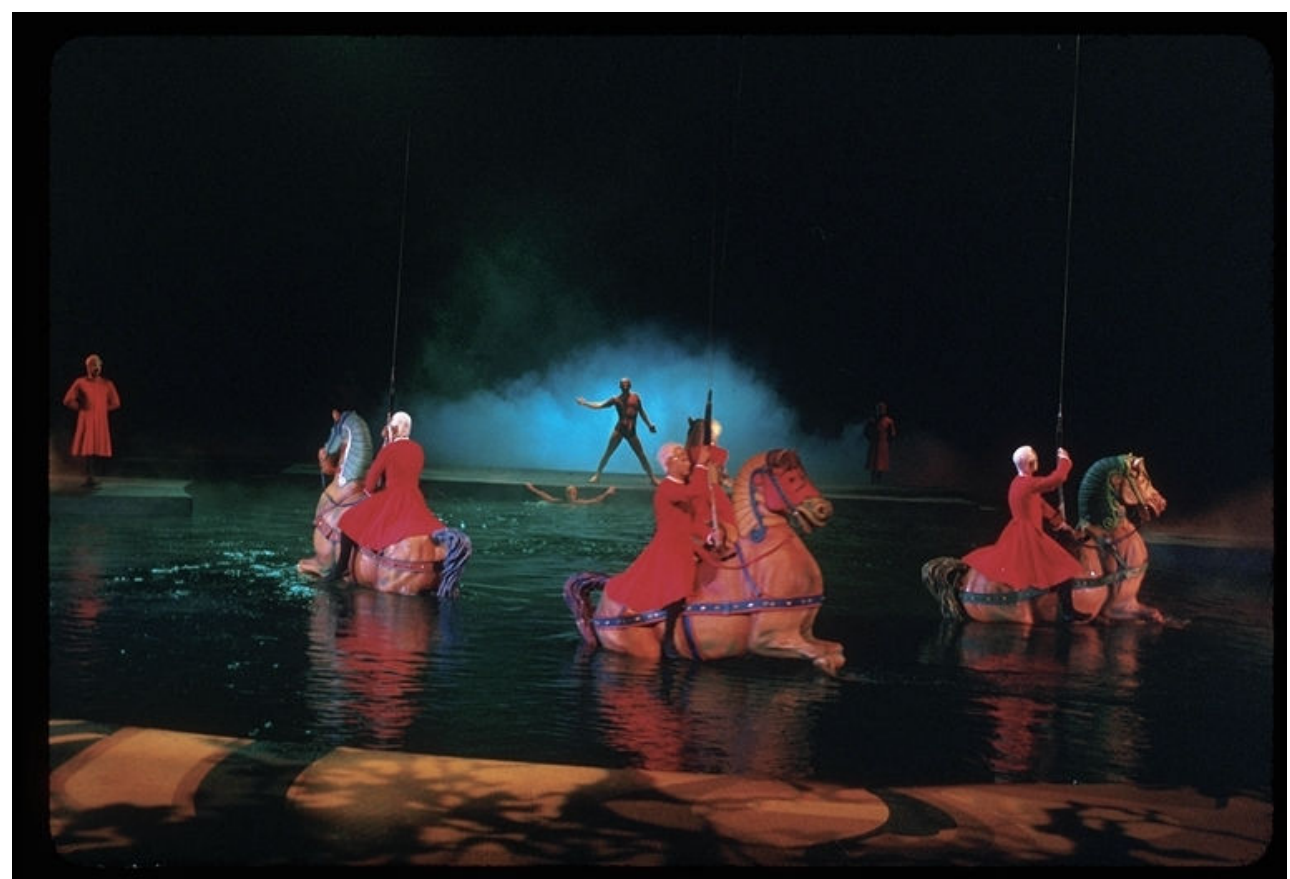

Figure 2. One of the sequences in the "O" show at the Bellagio that involves many underwater mechanisms to achieve the desired effects (photo compliments of Cirque d Soliel).

Proceedings of the 2005 American Society for Engineering Education Annual Conference \& Exposition Copyright $\mathbb{0}$ 2005, American Society for Engineering Education 


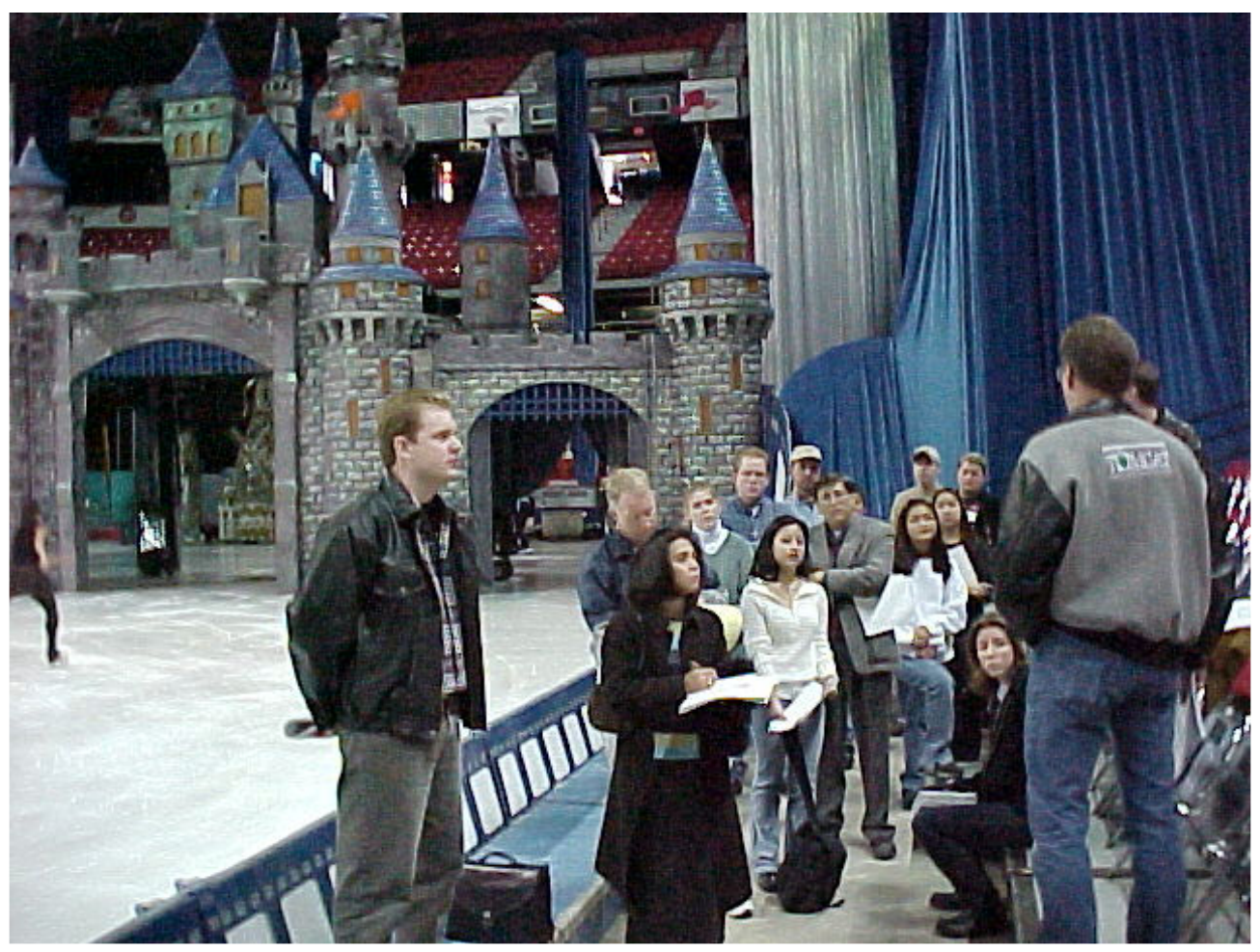

Figure 3. The "Disney on Ice" production is one of many that presents special challenges to allow the complete show, including a temporary ice rink in this case, to be set up in a variety of locations.

A key element of the new program is its interdisciplinary nature, which is desirable in this industry. While its target student audience is between Theatre and Engineering, students in a number of other fields, including other fine arts areas, business, hotel administration and humanities find some attraction to enroll.

Given the interdisciplinary background of the students, the biggest challenge is to know how to handle the technical elements for the non-technical majors, and the theatrical aspects for the majors outside of Theatre. Full traditional educational programs in either area of emphasis for students in the entertainment design area are not desirable unless the students opt for them.

The program must have a practical element to it. Partially this is a result of the nature of the students involved, and partially this is a result of the nature of the business. Much of what is done in the industry is quite "hands-on." An emphasis on design is critical to instill a practical element into the program. Although some graduates of the program are anticipated to be in operations-type positions they will still be expected to perform design functions on the job from time-to-time. 
Pertinent computer-aided design tools should be one of the topics addressed in the program. This does not mean graduates should be familiar with all computer tools. Nor do they need to be familiar with all of the background theory incorporated in the codes. Instead software is selected that could be of value to people in this industry and straightforward in application. Special efforts are expended to find software that fits this definition.

Practitioners play an active role in the program educational process. A range of possibilities can address this. Included are the uses of industrially affiliated lecturers and instructors, field trips to hear about and see actual practices, and internships with relevant organizations. In all cases, though, the program elements and the people and experiences sampled should meet sufficient levels of quality so that the program can gain a favorable reputation in the field.

Securing practitioners who are on the cutting edge of technological applications is not an easy task. These people tend to be very busy. Also, their schedules can be changed at the whim of a client. Trying to have these people commit to a specific date is very problematic. We have to be quite flexible and keep a variety of options open. One of our courses (outlined below) requires the use of 4 practitioners, each for approximately $25 \%$ of a semester course. This requires special selection of 4 people who have a good chance to be present during the full period of commitment.

The selection of regular faculty members to be involved is given special consideration. Since this is a totally new program and interdisciplinary in nature, finding faculty with appropriate background and interests can be difficult. While the program faculty will grow by acquiring new hires, this fact is not a panacea. Finding appropriate new faculty is not easy. If the new people are too practical, they may not be able to be successful in achieving tenure. If they are too academic in a traditional field, they may not have the ability to function well in this interdisciplinary milieu.

How the program is being initiated is an element of great concern. This is due partially to the fact that many universities (including ours) do not have the financial abilities to introduce new programs in a significant way. Since this is a totally new field currently not well defined, a slower development approach appears to be better. Some trial and correction is most probably needed as the program matures. Hence, we are initiating a minor; and after it is operating smoothly, we will move to a major program. Along the line, the appropriate types of labs and related facilities will have to be developed.

Elements of the program

We outline here some of the courses that make up the minor in Entertainment Engineering. Four courses specifically are used for illustrative purposes. Since this is early in the program, these courses will undoubtedly undergo change as they are developed. However, the discussion here is meant to give a flavor of the types of emphases found in the program.

A) Introduction to Entertainment Engineering

Proceedings of the 2005 American Society for Engineering Education Annual Conference \& Exposition Copyright $(\mathrm{C}$ 2005, American Society for Engineering Education 
This course is configured to give the student a general overview of the program. It is instructed by an academic team consisting of both engineers and technical theatre people, but it also draws upon practitioners. Various elements of the program are meant to introduce the student not only to the program, but also to different (creative, business, and technical) aspects of project development. A major element of both is a design aspect. Practitioners in this field are almost always in a design mode, whether it be for a totally new venue, or for improvements in an existing one.

To emphasize the practical side of the field, several professionals give invited lectures. These are people in the industry who have been found to have illuminating insights to the ins-and-outs of this business. They serve both to motivate as well as help the students understand the realities of the business.

Introductions to various technical aspects of the field take place in the course. Theatrical topics include the history of entertainment technology, story-boarding, theatrical flying, lighting, show control, and fire effects. Engineering coverage includes robotics, controls, materials, dynamic systems, electrical systems, and rides (both thrill rides and people movers).

A major emphasis of this course is a semester-long design exercise. This is performed by multidisciplinary teams of students. It usually involves the design of a venue with a particular theme. Students are then required to draw upon their backgrounds in developing the design using the approaches summarized in the course. Regular oral and written presentations are scheduled with the faculty serving as the client (the buyer) and the students representing a company with broad design services to sell. Students are also held to costing and timing aspects of the project. One emphasis is that the specific problem requirements are not outlined in great detail, as this is normally the way commercial projects are initiated. The teams must be involved in defining what will make an entertaining experience for the clients' customers, and in this way they attempt to demonstrate some aspects of creativity.

This course is offered yearly. We have had practitioners from as far away as New York City donate their services to the class.

\section{B) Theatrical Technologies}

Several aspects in traditional theatre developed over the years demonstrate a significant technical bent. Lighting equipment, show control systems, modern lifts, and general electrical design found in the theatre all require a reasonable level of technical understanding for successful applications. In our program these four topics have been combined into one course, which relies quite heavily on four practitioners to outline respective current technology and its use.

A special kind of instructor is sought for this course. Above all, the person needs be abreast of current technical theatre practice. The instructor also has to have the ability to commit for a period of one-fourth of a semester. Instructor continuity is critical. The type of individual we 
need for this course leads an active professional career with many on-the-job time demands. Additionally, the instructor should be able to demonstrate to the students actual systems of the type being discussed. In general we do not have cutting-edge versions of this equipment at the University, so we depend greatly upon the ability to visit commercial venues where these are more likely to be available. In this regard, our location in Las Vegas is extremely valuable.

\section{C) Animatronics}

Animatronics is a term that was made famous through Walt Disney's Imagineering efforts. Included in this is the development of machines able to perform lifelike actions. A combination of mechanisms, dynamic systems, controls and robotics all fit within this topic. Hence on one level, this could be a very advanced engineering course. However, the challenge here is to open the eyes of non-engineers and engineers alike to some pertinent elements without delving at great depth into the theory. Straightforward analysis tools allowing the user to perform design projects having automated temporal sequences are sought. The course is covered entirely by an engineering faculty member.

D) Practicum

Practicum is one of the final courses a student takes during her/his program. In fact there is a requirement that a large fraction of the courses need to be completed before this is undertaken.

The course involves credit for an approved affiliation with an organization that is related to the focus of our program, similar to an internship. It can include design, operations, regulation/inspection, and management of live entertainment venues. The student seeks out a position in the business, either by her-/himself and/or by consulting with program faculty. Prime considerations in choosing a position include the following:

- Must be at a professional or at least a semi-professional level for 120 hours duration.

- Must involve some aspects of entertainment technology in a predefined scope.

- Must have a technical person in the organization who can serve as the student's mentor.

When the student has chosen a possible potential affiliation for this course, a proposal to participate is filed with the faculty steering committee. Included in the application are statements addressing the three points above and a brief summary of what the student expects to gain from the experience. The steering committee then acts on the proposal, and, if successful, assigns a faculty advisor to the student for this project. If the proposal is not deemed to be appropriate, the steering committee works with the student to improve the proposal toward approval.

Approximately midway through the assignment, the student reports formally on the experience. This is required in both written and oral forms with the faculty advisor and professional mentor present. A similar set of reports is required at the end of the experience. 
Several outcomes for the student are expected from this experience. Firstly, she/he has gained some experience if this was missing previously. It also may put the student on an inside track to a post graduation job. Finally, it tends to bring the University in closer contact with practitioners.

\section{E) Other courses}

A total of 21 credits are required for a minor in the entertainment design program. The University requires a minimum of 18 credits for any minor, but we have opted for an additional course because this area may have no relationship to the student's major. We would like to have as much experience in it as is reasonable for a minor.

Additional courses not noted above are available to the students on a regular basis. Included are some not currently found in the conventional curricula and some that are included. In the former category there are classes in:

- Visualization

- Design creativity

Some existing courses in both engineering and theatre can be counted toward the program requirements. In general these courses are given credit in the program to the respective group of nonmajors. Engineering students can receive credit for a course in stage lighting theory, for example. Theatre students and those from other majors outside of engineering can receive credit for courses like Introduction to Engineering Design. The concern in the selection of these courses is that they not have a list of prerequisites that will significantly increase the student's requirements and thus prolong the time needed to complete the degree.

Plans for the future

As was noted earlier, the plan is to develop this program into a full major at UNLV. We anticipate this will take two years after the minor is operating smoothly. Development of a new major requires that many more details be worked out than are needed for the development of a minor. Instituting a new major at our school requires Regents approval. Included in this approval process are data showing the need for the major, support by practitioners, and estimates of the major's impact. We don't anticipate any problems, but it will require many details to be worked out.

Faculty members are being sought specifically for this program. Hiring the right types of individuals will not be straightforward because of the program's uniqueness. Not only is the topical material unique, but also the ability to work with practitioners to develop their support is especially critical. So far, practitioners have been extremely supportive of the effort.

One of the issues faced is developing academic research pertinent to the program thrust. Few Federal funding agencies have an interest in supporting this type of work. It is possible more 
traditional funding sources could find interest in some of the by-products of this research. One example from a related but distinct area is in the computer graphics arena. Computer graphics clearly has entertainment applications but also can be adapted to battlefield simulations, for instance. Adaptation of live venue entertainment to, say, DOD concerns, seems to have less potential. However, the probability of some applications finding funding in, for example, specialized approaches to lighting and animatronics, is in the realm of possibility.

To aid this effort, the University is developing research space for the thrust. A new Science, Engineering, and Technology building is currently under construction. This four-story facility will house four of the University's Macrothemes. Macrothemes have been developed from interdisciplinary efforts that drawing upon strengths of the University and that serve a perceived value to the state and local economy. Entertainment-related studies will be a part of this. A daunting task is planning for the type of research that might be performed in a major that does not exist anywhere at the current time by researchers who are, in general, not currently on the faculty. Unlike some other Macrothemes to be housed in this building (examples are wet chemistry-type labs in materials and energy), the Entertainment thrust will have sparselyoutfitted labs. These will include areas that can be used as spaces to set up special effects, and rooms where the lighting and sound can be closely controlled and evaluated free from external impacts.

\section{Conclusion}

The development of a new interdisciplinary program in Entertainment Engineering offers great and exciting challenges. It is argued that Las Vegas presents an ideal location for such a program and the University of Nevada Las Vegas is very supportive of this development. The availability of significant numbers of practitioners and actual cutting-edge venues in Las Vegas makes this a natural. Some of the new courses being developed for this program are outlined. The program is initially offered as a minor that can be taken with a variety of majors across the University. When the minor is completely instituted and student demand is demonstrated for it, the program will move to an interdisciplinary major.

Bibliography

[1] Daniel B. Wood, "In Vegas, a Class on Building Extravaganzas," The Christian Science Monitor, April 29, 2003, p. 3.

[2] M. Arnone, "A New Engineering Curriculum Tries to Make Magic," Chronicle of Higher Education, January 9, 2004, pp. A8, A9.

[3] D. Kushner, “Let Us Entertain You,” IEEE Spectrum, February 2004, pp. 58-60.

[4] Transcript of interview with R. Boehm, "Engineering and Theater Meet in New Entertainment Engineering Program," College Spotlight, October 2004, p. 7. 


\section{Biography}

JOE ALDRIDGE is Associate Professor and Technical Director in the UNLV Theatre Department. He received an MA from University of Nevada Las Vegas and has been affiliated with numerous production shows in the Las Vegas area and elsewhere. He currently serves as the Vice President for the United States Institute for Theatre Technology (USITT). He is a member of the executive committee for the developing Entertainment Technician Certification Program as a representative for USITT.

ROBERT BOEHM is Distinguished Professor of Mechanical Engineering at the University of Nevada Las Vegas and a graduate of the University of California at Berkeley. He has been awarded the Distinguished Teaching Award and the inaugural Harry Reid Silver State Research Award at the University. He is the author or coauthor of approximately 400 technical publications, a registered professional engineer, and a Fellow of the ASME.

BRACKLEY FRAYER is Associate Professor and Lighting Designer for the Theatre Department at the University of Nevada Las Vegas. Regional design credits include work with the Nevada Conservatory Theatre, Seven Stages-Atlanta, the Hippodrome Theatre, Texas Shakespeare Festival, New York Lyric Opera Company, and Oedipus at Colonus, in Dephi, Greece, for the International Meeting on Ancient Greek Drama. He received an MFA from the Yale School of Drama and is a member of United Scenic Artists, Local 829. 